\title{
Efficacy of heart transplantation in patients with a failing Fontan: a systematic review and meta-analysis
}

Wardah Hassan ${ }^{1}$, Sohny Kotak ${ }^{1}$, Mahima Khatri ${ }^{1}$, Areeba Ahmed ${ }^{1}$, Jawad Ahmed ${ }^{1 *}$ (D) Syed Saad Ali ${ }^{1}$ and Taj M. Khan ${ }^{2,3}$

\begin{abstract}
Background: As the population of patients with Fontan palliation grows, so does the number of patients with Fontan failure, necessitating heart transplantation. However, due to mainly small-sized studies, outcomes after heart transplantation in these patients remain unclear. The objective of this study was to review the available literature and conduct a meta-analysis to provide well-powered and generalizable estimates of outcomes after heart transplantation in patients with a failing Fontan.

Main text: PubMed, Embase, and MEDLINE databases were searched for original studies of patients with a failing Fontan who underwent heart transplantation. The outcomes included were 1-year and 5-year survival, acute rejection, renal dysfunction, sepsis, and multi-organ failure. Proportions were pooled using random effects models to derive pooled proportions (PPs) and corresponding 95\% confidence intervals (Cls). Meta-regression analysis was done to study the effects of age and gender on key outcomes. Sixteen retrospective single-center cohort studies with 426 Fontan patients undergoing heart transplantation were included in this meta-analysis. Pooled analysis of this study further revealed that 1-year survival after heart transplantation was $79.9 \%\left([75.8 \%, 83.7 \%] ; P^{2}=1.92 \%\right)$, and 5-year survival rate was $72.5 \%\left([62.1 \%, 81.9 \%] ; P^{2}=72.12 \%\right)$. Secondary outcomes after heart transplantation of failed Fontan procedure were acute rejection (PP 20\% [7.4\%, 36.8\%]; $P^{2}=72.48 \%$ ), renal dysfunction (PP 31.3\% [10.5\%, 57.2\%]; $P^{2}=75.42 \%$ ), multi-organ failure (PP 18.6\% [2.8 to 43.9\%]; $P^{2}=69.60 \%$ ), and sepsis (PP $21.1 \%[9 \%, 36.8 \%] ; P^{2}=$ 61.19\%).
\end{abstract}

Conclusion: Cardiac transplantation in patients with a failing Fontan is associated with acceptable interventional success and improved survival rates.

Keywords: Fontan, Adult congenital heart disease, Congenital heart surgery

\section{Background}

For over 50 years, procedures like Fontan have been performed for surgical treatment in patients with functionally univentricular hearts [1]. Principally, a Fontan circulation is created when the systemic and pulmonary circulations are placed in series with the single functional ventricle, i.e., redirecting blood from the inferior

\footnotetext{
* Correspondence: jawadahmedd13@gmail.com

'Department of Internal Medicine, Dow University of Health Sciences, Baba e Urdu Road, Karachi, Pakistan

Full list of author information is available at the end of the article
}

vena cava (IVC) and superior vena cava (SVC) into the pulmonary artery, bypassing the right ventricle completely. According to the American Heart Association (AHA), the worldwide population of patients with Fontan circulation grew from an estimated 50,000 to 70,000 patients in 2018, with $40 \%$ of patients $>18$ years of age. The current estimated survival rate following the Fontan procedure is approximately $85 \%$ [2]. Although this procedure significantly improves survival and quality of life, Dr. Fontan himself speculated that this procedure imposes a "gradually declining functional capacity and

\section{Springer Open}

(๑) The Author(s). 2021 Open Access This article is licensed under a Creative Commons Attribution 4.0 International License, which permits use, sharing, adaptation, distribution and reproduction in any medium or format, as long as you give appropriate credit to the original author(s) and the source, provide a link to the Creative Commons licence, and indicate if changes were made. The images or other third party material in this article are included in the article's Creative Commons licence, unless indicated otherwise in a credit line to the material. If material is not included in the article's Creative Commons licence and your intended use is not permitted by statutory regulation or exceeds the permitted use, you will need to obtain permission directly from the copyright holder. To view a copy of this licence, visit http://creativecommons.org/licenses/by/4.0/. 
premature late death... the Fontan operation is, therefore, palliative but not curative" [3]. By the same token, patients with Fontan failure may present with growth failure, lymphatic failure, ventricular dysfunction, extracardiac organ failure, and decreased functional status (low oxygen consumption VO2) [3].These manifestations may occur early in the postoperative period or late during the long-term follow-up, all indicating towards the need for immediate heart transplantation [4]. Nevertheless, there have been concerns that even after transplantation these patients are at high risk for complications because of multiple prior operations, elevated panel reactive antibody, pre-transplant hepatic dysfunction, coagulopathy, protein-losing enteropathy (PLE), and poor nutrition [5, 6]. However, actual posttransplant outcomes in this population are poorly understood due to mainly small-sized studies with varying findings. Thus, we conducted a meta-analysis to provide well-powered and generalizable estimates of primary survival and other secondary outcomes such as acute rejection, sepsis, renal dysfunction, and multi-organ failure after heart transplantation in patients with a failing Fontan.

\section{Materials and methods}

This meta-analysis conforms to the guidelines set by Preferred Reporting Items for Systemic Review and Meta-analysis (PRISMA) [7].

\section{Search strategy}

A systematic literature search was conducted up till December 10, 2020, on PubMed, Embase, and MEDLINE databases with the following subject keywords and their $\mathrm{MeSH}$ terms: (heart transplantation, cardiac transplantation, new heart, heart engraftment, heart grafting, heart grafts, heart implantation, heart implants, heart-lung transplantation, heart transplants) AND (failing heart, Fontan procedure failure, Fontan method, Fontan process, Fontan technique, ventricularization of the right atrium, aortopulmonary connection, intracardiac total cavopulmonary connections, extracardiac total cavopulmonary connection).

Two reviewers independently screened the search results. A third reviewer was consulted in case of discrepancies. Studies were initially shortlisted based on title and abstract, after which the full-text was assessed for eligibility. References of the selected studies were also reviewed thoroughly to prevent any risk of selection bias.

\section{Study inclusion and exclusion criteria}

Studies were eligible with consideration of the following inclusion criteria: (1) published full text and in the English language, (2) patients with a failing Fontan procedure were included, and (3) 1-year and/or 5-year survival after cardiac transplantation was reported with the inclusion of both adult (age $\geq 18$ years) and pediatric populations. The pediatric population was defined as < 18 years. Moreover, studies were carefully assessed if they had provided the required data for survival and morbidity of failed Fontan patients separately and were excluded if not. Articles were excluded if they were reviews, editorials, or case reports.

\section{Data extraction}

Data extraction of the relevant studies included the first author, year of publication, type of study (cohort or randomized controlled trial), study follow-up time, and the total number of patients who underwent heart transplantation. Baseline characteristics and indications for transplantation were also extracted. Primary outcomes of 1-year and 5-year survival rates were extracted by careful screening of Kaplan-Meir survival curves (KM) of the individual studies. Secondary outcomes of acute rejection, sepsis, renal dysfunction, and multi-organ failure were only included if three or more studies reported them. Renal dysfunction was defined as patients requiring renal replacement therapy such as continuous venovenous hemodialysis and hemodialysis, while multiorgan failure was defined as patients having heart, lung, and liver. The included articles, however, did not mention any specific definition for sepsis; thus, the primary study investigator's definition of sepsis-the body's extreme response to an infection-was accepted.

\section{Assessment of risk of bias}

Quality assessment of all the observational studies was done by using the Newcastle-Ottawa reference scale [8].

\section{Data analysis}

All the extracted data was statistically analyzed using the OpenMetaAnalyst software (Center for Evidence Synthesis in Health, Brown University). The categorical variables were tabulated in the form of proportions, and arcsine transformation was appertained. Proportions of 1-year and 5-year survival and all the secondary outcomes were pooled using both random and fixed effects models. The $I^{2}$ statistic was used to analyze the heterogeneity, with a value of $>75 \%$ labeled as severe heterogeneity of the data [9]. In addition to that, we also conducted a multivariate meta-regression analysis to assess the association between risk ratio (RR) and age and gender (males) of Fontan patients. A $p$-value of $<0.05$ was considered significant.

\section{Ethics committee approval}

This is a systematic review that uses publicly available data, therefore, does not require any ethical approval. 


\section{Results}

The initial search revealed a total of 187 studies. After exclusions, 16 studies [10-25], published between 1995 and 2017, were included in the meta-analysis. The PRIS MA figure summarizing the literature search is labeled as Fig. 1. These studies included 426 patients with a failing Fontan who underwent heart transplantation.

\section{Study characteristics and quality assessment}

All the studies employed in this meta-analysis were retrospective, observational, and large single-center, covering heart transplantations over 33 years (1955 to 2017) with a sample size ranging from 3 to 194 subjects. Out of the 16 studies, 14 reported details regarding age at transplantation $[10-15,17-20,22-25]$, thereby, determining a mean age of 21.4 years from a sample of 426 Fontan patients. Almost three-fourth $(72.5 \% ; N=309)$ of the patients were males. Indications for transplantation reported in some studies were protein-losing enteropathy (PLE) in $35.6 \%$ of patients, tricuspid atresia in $39 \%$ of patients, double inlet left ventricle in $27.15 \%$ of patients, hypoplastic left heart in $16.8 \%$ of patients, and heterotaxy in $18.9 \%$ of patients. Table 1 shows the detailed study baseline characteristics. Quality assessment of included studies (Table S1) showed that most studies had a low risk of bias.

\section{One-year and 5-year survival rate}

Fifteen studies reported survival rate at 1 year and 5 years. The pooled prevalence (PP) of 1-year survival rate among Fontan patients was $79.9 \%\left([75.8 \%, 83.7 \%] ; I^{2}=\right.$ $1.92 \%)$, and 5 -year survival rate was $72.5 \%$ ([62.1\%, 81.9\%]; $I^{2}=72.12 \%$ ) as shown in Fig. 2 a and b, respectively.

Multivariate meta-regression analysis revealed that age [1-year survival rate $(\mathrm{RR}=-0.02 ; p=0.288), 5$-year survival rate $(\mathrm{RR}=-0.017 ; p=0.447)]$ and male gender $[1$ year survival rate $(\mathrm{RR}=-0.002 ; p=0.770)$, 5 -year survival

PRISMA 2009 Flow Diagram
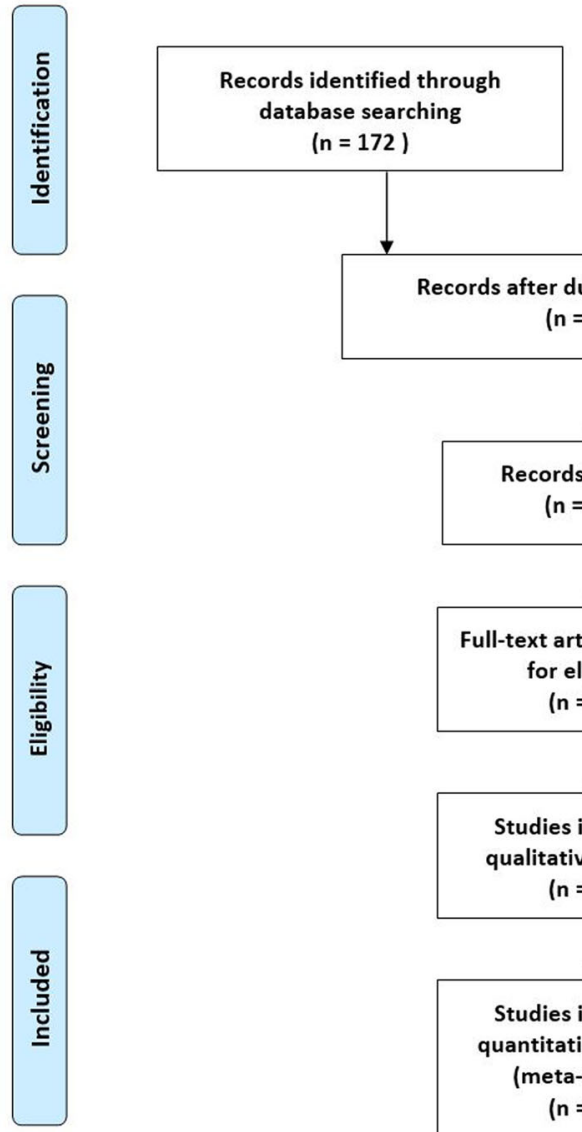

Additional records identified through other sources ( $n=172$ ) ( $n=15$ )
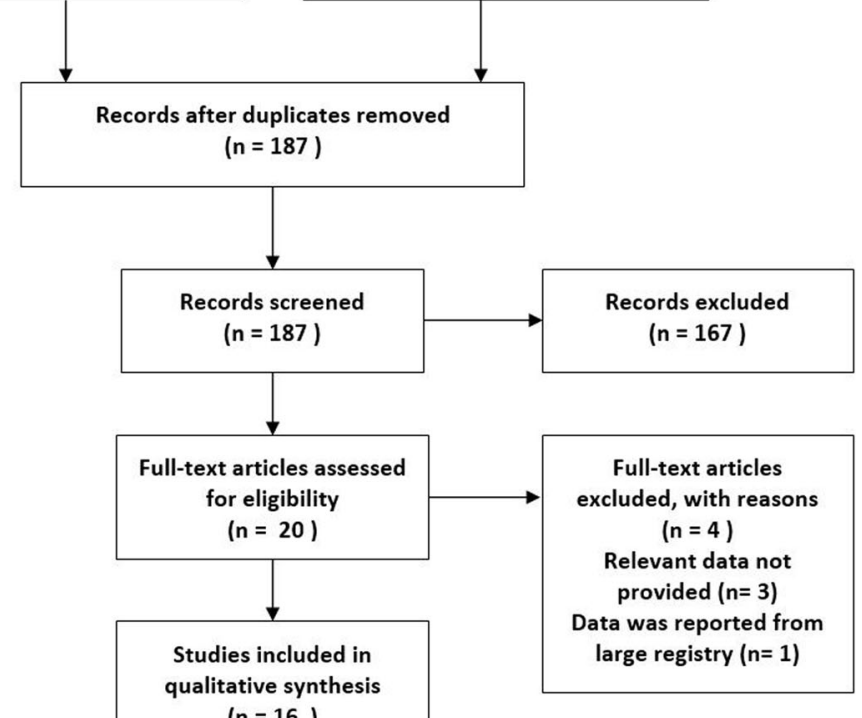
( $n=16$ )

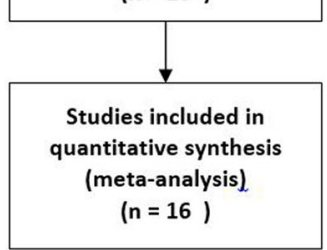

Fig. 1 PRISMA flow chart summarizing the literature search 


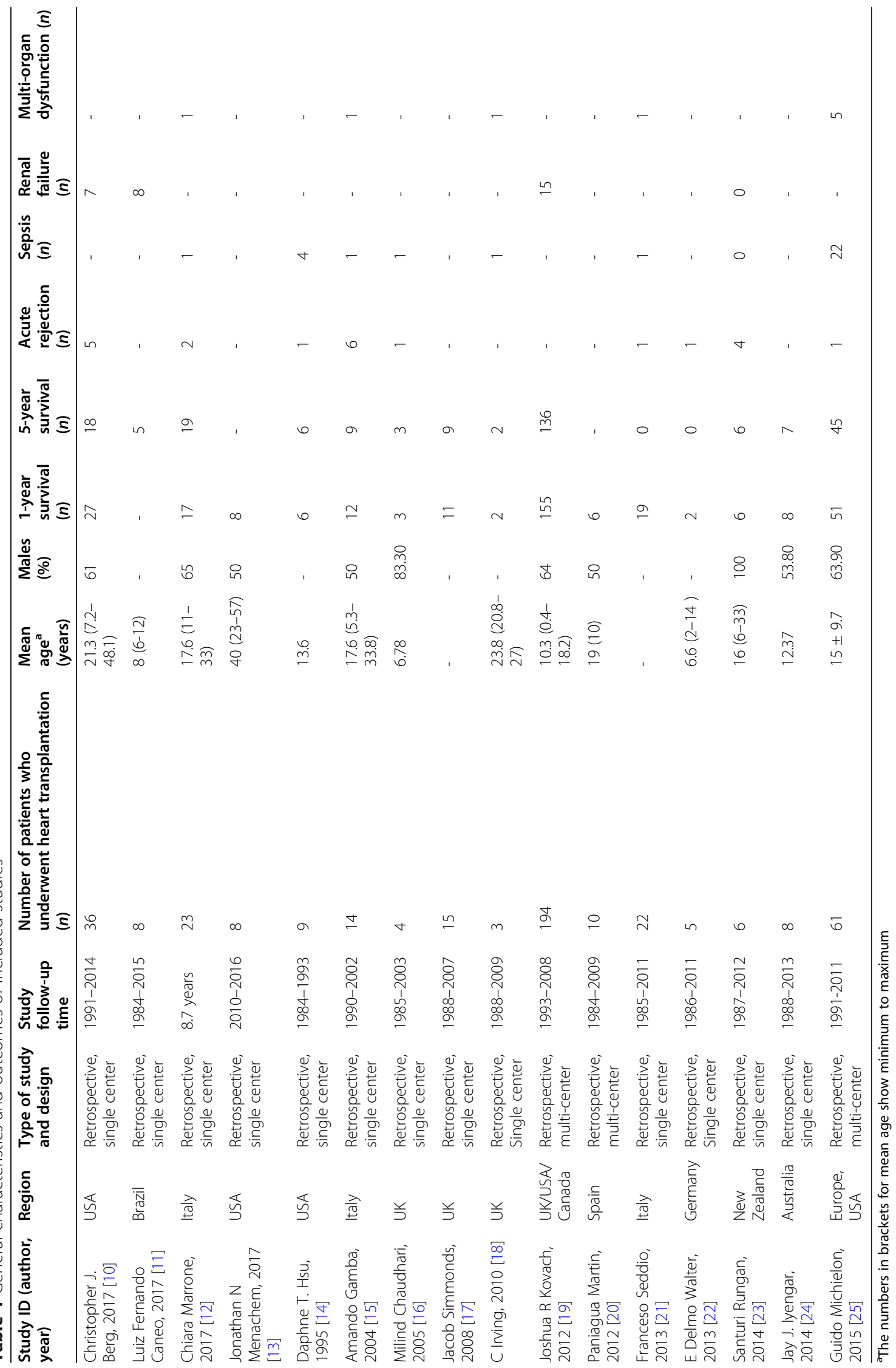




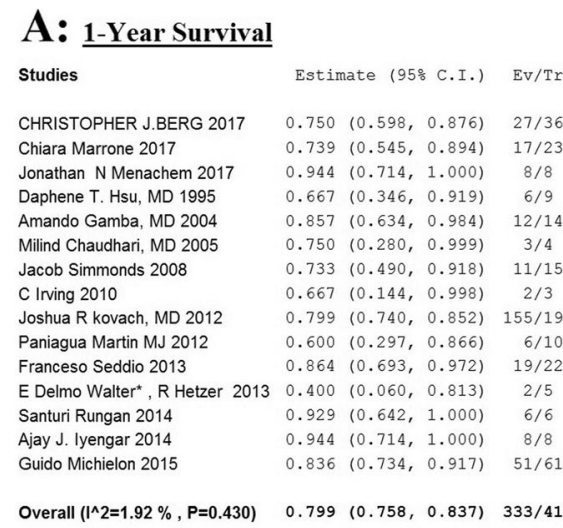

\section{B: 5-Year Survival}

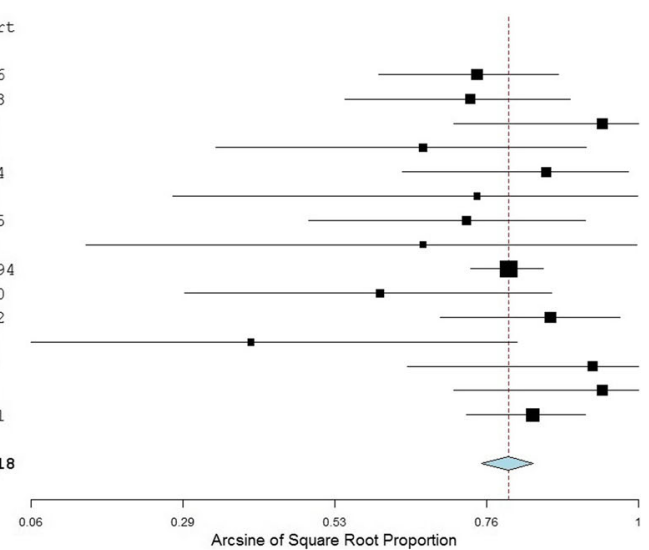

\begin{tabular}{|c|c|c|c|c|}
\hline tudies & Esti & mate 1958 & C.I & \\
\hline CHRISTOPHER J.BERG 2017 & 0.500 & $(0.340$, & $0.660)$ & \\
\hline Luiz Fernando Caneo 2017 & 0.625 & $(0.287$, & $0.905)$ & \\
\hline Chiara Marrone 2017 & 0.826 & $(0.649$ & $0.950)$ & \\
\hline Daphene T. Hsu, MD 1995 & 0.667 & 10.346 & $0.919)$ & \\
\hline Amando Gamba, MD 2004 & 0.643 & 10.384 & $0.863)$ & \\
\hline Milind Chaudhari, MD 2005 & 0.750 & 10.280 & $0.999)$ & \\
\hline Jacob Simmonds 2008 & 0.600 & 10.350, & $0.825)$ & \\
\hline C Irving 2010 & 0.667 & 10.144 & $0.998)$ & \\
\hline vach, MD 2012 & 0.701 & $(0.635$ & $0.763)$ & \\
\hline Paniagua Martin MJ 2012 & 0.955 & 10.761, & $1.000)$ & \\
\hline Franceso Seddio 2013 & 0.978 & 10.881 & $1.000)$ & \\
\hline E Delmo Walter*, R Hetzer 2013 & 0.917 & 10.592, & $1.000)$ & \\
\hline Santuri $\mathrm{F}$ & 0.071 & 10.000 & $0.358)$ & \\
\hline Ajay J. I & 0.875 & 10.577 & $1.000)$ & \\
\hline Guido Michielon 2015 & 0.738 & $(0.621$, & $0.839)$ & \\
\hline
\end{tabular}

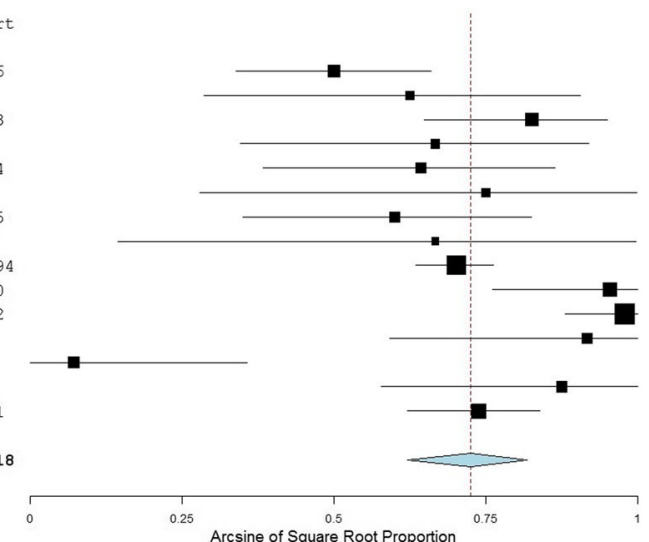

Fig. 2 Forest plots for survival outcomes of heart transplantation after failed Fontan for a 1-year and b 5-year. $\mid \wedge 2$, heterogeneity; 95\% Cl, 95\% confidence interval; Evt/Trt, events/total

rate $(\mathrm{RR}=0.00 ; p=0.99)]$ had an insignificant negative correlation with both the survival rates respectively.

\section{Secondary outcomes}

Figure 3 shows forest plots for secondary outcomes of heart transplantation after failed Fontan procedure. The prevalence of acute rejection was $20 \%$ ([7.4\%, 36.8\%]; $I^{2}$ $=72.48 \%$ ) (Fig. 3a), renal dysfunction was $31.3 \%$ ([10.5\%, $57.2 \%] ; \mathrm{I}^{2}=75.42 \%$ ) (Fig. 3b), multi-organ failure was $18.6 \%$ ([2.8 to $43.9 \%] ; I^{2}=69.60 \%$ ) (Fig. 3c), and sepsis was $21.1 \%\left([9.0 \%, 36.8 \%] ; I^{2}=61.19 \%\right)$ (Fig. 3d).

\section{Sensitivity analysis of pediatric population}

Furthermore, a sensitivity analysis was also conducted to identify the survival rate among the pediatric population separately who underwent heart transplantation for failed Fontan. The analysis yielded a pooled prevalence of $74.5 \%$ ([65.4\%, 82.5\%]; $I^{2}=14.85 \%$ ) for 1 -year survival rate (Figure S1) and $69.2 \%\left([63.1 \%, 75 \%] ; I^{2}=0 \%\right)$ for 5 -year survival rate (Figure S2) in pediatric population.

\section{Sensitivity analysis of low bias studies}

To assess the risk of bias, a sensitivity analysis was done for 1-year and 5-year survival rate by excluding studies that had a medium risk of bias (Figure S3-S4). The new pooled prevalence for 1-year survival was $80.3 \%$ ([75.3\%, $\left.84.8 \%] ; I^{2}=11.83 \%\right)$ and for 5 -year survival was $73.6 \%$ ([62.3\%, 82.6\%]; $\left.I^{2}=75.62 \%\right)$.

\section{Sensitivity analysis of studies with $\geq 10$ patients}

Another sensitivity analysis was done to find the effect of sample size on heterogeneity by including only those studies that had $\geq 10$ patients (Figure S5-S6). The 1-year survival rate was $79.6 \%$ ([75.4\%, 83.6\%]; $I^{2}=0 \%$, and 5-year survival rate was $75.8 \%$ ([64.2\%, $\left.85.7 \%] ; I^{2}=77.6 \%\right)$. Sample size ( $\geq 10$ patients) sensitivity analysis was able to reduce heterogeneity to $0 \%$ in 1-year survival rate. Furthermore, leave-one-out sensitivity analyses were done for 5-year survival rate outcome, but no study was found whose removal reduced heterogeneity. 


\section{A (Acute Rejection)}

\section{Studies}

CHRISTOPHER J.BERG 2017 Jonathan N Menachem 2017 Daphene T. Hsu, MD 1995 Amando Gamba, MD 2004 Paniagua Martin MJ 2012 Franceso Seddio 2013 $0.045(0.000,0.169)$ Ajay J. lyengar 2014

Overall $\left(\left.\right|^{\wedge} 2=72.48 \%, P<0.001\right) \quad 0.200 \quad(0.074,0.368) \quad 20 / 112$

\section{B (Renal Dysfunction)}

Studies

CHRISTOPHER J.BERG 2017

Luiz Fernando Caneo 2017

C Irving 2010

Overall $\left(\left.\right|^{\wedge} 2=75.42 \%, P=0.017\right) \quad 0.313(0.105,0.572)$

\section{C (Multi-organ Failure)}

Estimate (95\% C.I.) Ev/Trt

$0.194(0.084,0.338)$ $0.615(0.347,0.850)$ $0.200(0.044,0.431)$

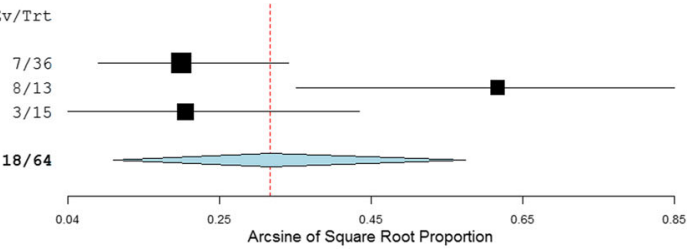

Studies

Daphene T. Hsu, MD. 1995 Jacob Simmonds 2008 Paniagua Martin MJ 2012 Ajay J. Iyengar 2014

Estimate (95\% C.I.) Ev/Trt

D $\underline{\text { (Sepsis) }}$

$0.111(0.000,0.382)$ $0.067(0.000,0.242)$ $0.100(0.000,0.349)$ $0.625(0.287,0.905)$

$0.186(0.028,0.439)$

$$
1 / 15
$$

$$
1 / 10
$$

$$
5 / 8
$$

$8 / 42$

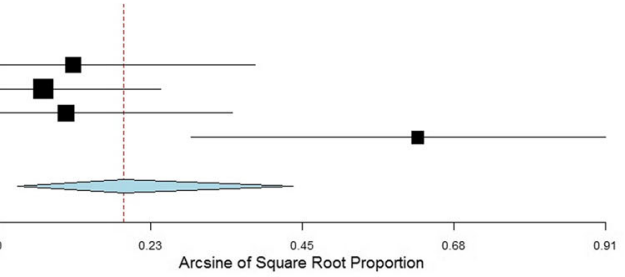

Estimate (95\% C.I.) Ev/Trt

$0.500(0.181,0.819)$ $0.500(0.181,0.819)$ $0.111(0.000,0.382)$ $0.071(0.000,0.258)$ $0.067(0.000,0.242)$ $0.067(0.000,0.242)$ $0.364(0.180,0.571)$ Jacob Simmonds, 2008 Paniagua Martin MJ 2012 Ajay J. Iyengar 2014

$0.211(0.090,0.368)$

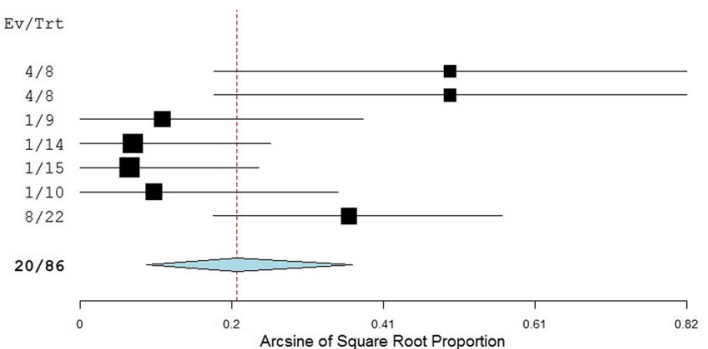

Fig. 3 Forest plots for safety outcomes: a acute rejection, b renal dysfunction, c multi-organ failure, and $\mathbf{d}$ sepsis. $\mid \wedge 2$, heterogeneity; $95 \%$ Cl, $95 \%$ confidence interval; Evt/Trt, events/total

\section{Discussion}

This updated meta-analysis provides a reliable evaluation of heart transplantation outcomes in patients with a failing Fontan. Although the Fontan procedure has been a symbolic contribution to the field of congenital heart surgery, it has its debacles. Many of the patients with Fontan will ultimately develop its failure [3]. Management of a failing Fontan consists of prolonging the state of Fontan circulation with the primary intention of making the patients better candidates for transplantation. Fontan failure is historically resistant to medical therapy, although the use of standard heart failure vasodilators and pulmonary anti-hypertensive drugs is part of the clinical management to help bridge patients to a more definitive surgical solution [26]. Mechanical circulation can be considered an option in cases of primary systemic ventricular dysfunction, predominantly the right side as the preeminent cause of Fontan failure [27, 28]. Surgical options for a failing Fontan are Fontan conversion and heart transplantation [29]. Fontan conversion usually consists of the construction of a bi-directional Glenn anastomosis, right atrial reduction, and placement of an extracardiac inferior vena cava to pulmonary artery conduit $[30,31]$. Although the total cavopulmonary connection (TCPC) has provided better early and intermediate outcomes for Fontan conversion [32], patients are at increased risk of heart failure or end-organ dysfunction during long-term follow-up [33-36]. On the other hand, 
the results of heart transplantation have improved significantly over the past decade [37-39].

Our study inclusive of 426 patients revealed 1- and 5year survival rates of $79.9 \%$ and $76.7 \%$ respectively. In this study, we confirmed that there is no association between transplant recipient age or gender and survival, revealed by multivariate meta-regression which showed that age $(R R=-0.014 ; p=0.196)$ and male gender $(R R=$ $-0.003 ; p=0.694$ ) had a nonsignificant negative correlation with 1-year survival rate whereas male gender had a significant negative correlation $(\mathrm{RR}=-0.014 ; p=0.002)$ with 5-year survival rate. In addition to these results, this study revealed that the incidence of PLE was considerably high among patients with a failing Fontan, but no significant association was found between PLE and 1and 5-year survival. However, PLE patients have been shown to have a high systemic venous pressure, low cardiac index, high pulmonary vascular resistance, decreased left ventricular systolic function, and elevated systemic ventricular end-diastolic pressure [40, 41], thus leading to an increase in Fontan pressure. Therefore, patients with PLE should be considered for heart transplantation. Furthermore, our analysis prompted that tricuspid atresia and double inlet left ventricle were found to present in a large number of Fontan patients requiring heart transplantation.

Compared to the previous study [42], which included a total of 351 patients, a significant number of patients and four observational studies have been added. The results of our analysis are consistent with the previous analysis, which revealed 1 - and 5-year survival rates of $79.9 \%$ and $72.5 \%$, respectively, with no significant association of age and gender with survival rates. The high heterogeneity in pooled results at 1-year and 5-year survival rate after exclusion of medium risk of bias studies can be attributed to many small studies with varying numbers of patients (from 4 to 194). In both our analysis and previous study, it has been difficult to ascertain the relationship of other factors with outcomes due to the heterogeneous nature of the population.

This study also revealed that the incidence of renal dysfunction after heart transplant was found to be significantly high (31.3\%) among our included Fontan patients. Post-transplant renal dysfunction has a multifactorial etiology, the most common being the calcineurin inhibitorinduced nephrotoxicity [43], which could be aggravated in patients with a poor pre-transplant renal reserve [44]. Other non-immunosuppression-related risks include impaired renal function before heart transplant, age at transplant, female gender, pre-transplant diabetes, hypertension, hyperlipidemia, atherosclerosis, and surgical factors (i.e., prior cardiac surgery, use of cardiopulmonary mechanical support) [45]. Therefore, kidney function should be assessed prior to a heart transplant, so that appropriate measures could be taken to prevent the renal function from deteriorating. Other than renal dysfunction, acute rejection (20\%), multi-organ failure (18.6\%), and sepsis (21.1\%) were also reported among our posttransplant population.

\section{Limitations}

This study has potential limitations. The effect estimates in the model are based on retrospective observational, single-center studies with a few multi-center studies. Therefore, they are subject to biases and confounding that may have influenced our results. We excluded patients with any underlying comorbidity like diabetes, hypertension, and patients with a history of prior transplantation. Most of the studies included in our study did not report data related to baseline characteristics of Fontan patients specifically. Despite trying to pursue the investigators of respective studies, we could not get access to the data related to prompting the need for heart transplantation in the Fontan population; a definite relationship could not be established. Therefore, more studies should be conducted in the future to determine the role of underlying heart conditions in the failure of Fontan. The relationship of other factors with outcomes could not be ascertained in our analysis due to the heterogeneity of the population. In addition to these, the data available was mostly related to the pediatric Fontan population, with only a few studies, including adult patients. Consequently, outcomes of heart transplantation in the adult population could not be determined. Furthermore, due to limited data available on the underlying heart conditions in adult Fontan patients, more studies should be conducted in the future.

\section{Conclusions}

As the results of this study exhibit increased survival rates among post-transplant patients, heart transplantation can be regarded as a standard option for patients with a failing Fontan. To further gauge the effectiveness of heart transplantation among patients with a failing Fontan, future researches should focus on the effects of underlying heart conditions on post-transplant outcomes and heart transplantation in the adult population with a failing single ventricle. Efforts should be made to optimize patient selection and the timing of transplantation in the hope of decreasing the significant early mortality and morbidity seen in this group.

\section{Supplementary Information}

The online version contains supplementary material available at https://doi. org/10.1186/s43057-021-00043-6.

Additional file 1 : Table S1. Quality assessment of cohort studies by Newcastle-Ottawa scale. Figure S1. Sensitivity analysis of 1-year survival 
rate including only pediatric population. Figure S2. Sensitivity analysis of 5-year survival rate including only pediatric population. Figure $\mathbf{S 3}$. Sensitivity analysis of 1-year survival rate including only low bias studies. Figure S4. Sensitivity analysis of 5-year survival rate including only low bias studies. Figure S5. Sensitivity analysis of 1-year survival rate including only studies with $\geq 10$ patients. Figure $\mathbf{S 6}$. Sensitivity analysis of 1-year survival rate including only studies with $\geq 10$ patients.

\section{Abbreviations}

IVC: Inferior vena cava; SVC: Superior vena cava; AHA: American Heart Association; PP: Pooled proportions; RR: Risk ratio; PLE: Protein-losing enteropathy; TCPC: Total cavopulmonary connection

\section{Acknowledgements}

None.

\section{Authors' contributions}

WH contributed to data extraction, quality assessment, and manuscript writing. SK contributed to quality assessment, literature search, and manuscript writing. MK contributed to the literature search and manuscript writing. AA extracted, interpreted, and analyzed data. JA contributed to data analysis and interpretation and critically revised the manuscript. SSA contributed to data analysis and manuscript writing. TMK contributed to data interpretation and critically revised the manuscript. All authors have read and approved the final version of the manuscript to be submitted and agree to be responsible for the accuracy of the content.

\section{Funding}

No funding was received for this study.

\section{Availability of data and materials}

The datasets used and/or analyzed during the current study are available from the corresponding author on reasonable request.

\section{Ethics approval and consent to participate}

This is a systematic review that uses publicly available data, therefore, does not require any ethical approval.

\section{Consent for publication}

Not applicable as no direct patients were involved in the study.

\section{Competing interests}

The authors declare no competing interests.

\section{Author details}

'Department of Internal Medicine, Dow University of Health Sciences, Baba e Urdu Road, Karachi, Pakistan. ${ }^{2}$ Pediatrics, Baylor College of Medicine, Houston, USA. ${ }^{3}$ Pediatrics, Texas Children's Hospital, Houston, USA.

\section{Received: 31 December 2020 Accepted: 14 February 2021}

\section{Published online: 25 February 2021}

\section{References}

1. Gewilling M (2005) The Fontan circulation. Heart. 91(6):839-846

2. Rychik J, Atz AM, Celermajer DS, Deal BJ, Gatzoulis MA, Gewillig MH, Hsia TY, Hsu DT, Kovacs AH, McCrindle BW, Newburger JW (2019) Evaluation and management of the child and adult with Fontan circulation: a scientific statement from the American Heart Association. Circulation. 140(6):e234e284

3. McCormick AD, Schumacher KR (2019) Transplantation of the failing Fontan. Transl Pediatr 8(4):290-301

4. Huddleston CB (2007) The failing Fontan: options for surgical therapy. Pediatr Cardiol 28(6):472-476

5. Backer CL (2016) Rescuing the failing Fontan. Heart. 102(14):1077-1078

6. Fontan F, Baudet E (1971) Surgical repair of tricuspid atresia. Thorax. 26(3): 240. https://doi.org/10.1136/thx.26.3.240

7. Liberati A, Altman DG, Tetzlaff J et al (2009) The PRISMA statement for reporting systematic reviews and meta-analyses of studies that evaluate health care interventions: explanation and elaboration. PLoS Med 6(7): e1000100
8. Wallace BC, Dahabreh IJ, Trikalinos TA, Lau J, Trow P, Schmid CH (2012) Closing the gap between methodologists and end-users: $\mathrm{R}$ as a computational back-end. J Stat Softw 49(5):1-15

9. Higgins JPT, Thompson SG, Deeks JJ, Altman DG (2003) Measuring inconsistency in meta-analyses. BMJ. 327(7414):557-560

10. Berg CJ, Bauer BS, Hageman A, Aboulhosn JA, Reardon LC (2017) Mortality risk stratification in Fontan patients who underwent heart transplantation. Am J Cardiol 119(10):1675-1679

11. Caneo LF, Turquetto ALR, Neirotti RA et al (2017) Lessons learned from a critical analysis of the Fontan operation over three decades in a single institution. World J Pediatr Congenit Heart Surg 8(3):376-384. https://doi. org/10.1177/2150135117701405

12. Marrone C, Ferrero P, Uricchio N, Sebastiani R, Vittori C, Ciuffreda M et al (2017) The unnatural history of failing univentricular hearts: outcomes up to 25 years after heart transplantation. Interact Cardiovasc Thorac Surg 25:892-897

13. Menachem JN, Golbus JR, Molina M et al (2017) Heart 103:1449-1454

14. Hsu DT, Quaegebeur JM, Michler RE, Smith CR, Rose EA, Kichuk MR, Gersony WM, Douglas JF, Addonizio LJ (1995) Heart transplantation in children with congenital heart disease. J Am Coll Cardiol 26(3):743-749

15. Gamba A, Merlo M, Fiocchi R, Terzi A, Mammana C, Sebastiani R, Ferrazzi P (2004) Heart transplantation in patients with previous Fontan operations. J Thorac Cardiovasc Surg 127(2):555-562

16. Chaudhari M, Sturman J, O'Sullivan J, Smith J, Wrightson N, Parry G, Bolton D, Haynes S, Hamilton L, Hasan A (2005) Rescue cardiac transplantation for early failure of the Fontan-type circulation in children. J Thorac Cardiovasc Surg 129(2):416-422

17. Simmonds J, Burch M, Dawkins H, Tsang V (2008) Heart transplantation after congenital heart surgery: improving results and future goals. Eur J Cardiothorac Surg 34(2):313-317

18. Irving C, Parry G, O'sullivan J, Dark JH, Kirk R, Crossland DS, Chaudhari M, Griselli M, Hamilton JR, Hasan A (2010) Cardiac transplantation in adults with congenital heart disease. Heart. 96(15):1217-1222

19. Kovach JR, Naftel DC, Pearce FB, Tresler MA, Edens RE, Shuhaiber JH, Blume ED, Fynn-Thompson F, Kirklin JK, Zangwill SD (2012) Comparison of risk factors and outcomes for pediatric patients listed for heart transplantation after bidirectional Glenn and after Fontan: an analysis from the Pediatric Heart Transplant Study. J Heart Lung Transplant 31(2):133-139

20. Paniagua Martín MJ, Almenar L, Brossa V, Crespo-Leiro MG, Segovia J, Palomo J, Delgado J, González-Vílchez F, Manito N, Lage E, García-Guereta L (2012) Transplantation for complex congenital heart disease in adults: a subanalysis of the Spanish Heart Transplant Registry. Clin Transplant 26(5): 755-763

21. Seddio F, Gorislavets N, lacovoni A, Cugola D, Fontana A, Galletti L, Terzi A, Ferrazzi P (2013) Is heart transplantation for complex congenital heart disease a good option? A 25-year single centre experience. Eur J Cardiothorac Surg 43(3):605-611

22. Walter ED, Ovroutski S, Hetzer R (2013) Heart transplantation in singleventricle physiology with failed Fontan circulation. Thorac Cardiovasc Surg 61(S 01):OP32

23. Rungan S, Finucane K, Gentles T, Gibbs HC, Hu R, Ruygrok PN (2014) Heart transplantation in pediatric and congenital heart disease: a single-center experience. World J Pediatr Congenit Heart Surg 5(2):200-205

24. Iyengar AJ, Sharma VJ, Weintraub RG, Shipp A, Brizard CP, d'Udekem Y, Konstantinov IE (2014) Surgical strategies to facilitate heart transplantation in children after failed univentricular palliations: the role of advanced intraoperative surgical preparation. Eur J Cardiothorac Surg 46(3):480-485

25. Michielon G, van Melle JP, Wolff D, Di Carlo D, Jacobs JP, Mattila IP, Berggren H, Lindberg H, Padalino MA, Meyns B, Prêtre R (2015) Favourable mid-term outcome after heart transplantation for late Fontan failure. Eur J Cardiothorac Surg 47(4):665-671

26. Silversides CK, Salehian O, Oechslin E et al (2010) Canadian Cardiovascular Society 2009 consensus conference on the management of adults with congenital heart disease: complex congenital cardiac lesions. Can J Cardiol 26:98-117

27. Morales DLS, Adachi I, Heinle JS et al (2011) A new era: use of an intracorporeal systemic ventricular assist device to support a patient with a failing Fontan circulation. J Thorac Cardiovasc Surg 142:138-140

28. Prêtre R, Häussler A, Bettex D et al (2008) Right-sided univentricular cardiac assistance in a failing Fontan circulation. Ann Thorac Surg 86:1018-1020

29. De Rita F, Crossland D, Griselli M, Hasan A (2015) Management of the failing Fontan. Semin Thorac Cardiovasc Surg Pediatr Card Surg Annu 18(1):2-6 
30. McElhinney DB, Reddy VM, Moore P et al (1996) Revision of previous Fontan connections to extracardiac or intraatrial conduit cavopulmonary anastomosis. Ann Thorac Surg 62:1276-1283

31. Marcelletti CF, Hanley FL, Mavroudis C et al (2000) Revision of previous Fontan connections to total extracardiac cavo-pulmonary anastomosis: a multicenter experience. J Thorac Cardiovasc Surg 119:340-346

32. Marcelletti CF, Hanley FL, Mavroudis C, McElhinney DB, Abella RF, Marianeschi SM et al (2000) Revision of previous Fontan connection to total extracardiac cavopulmonary anastomosis: a multicenter experience. J Thorac Cardiovasc Surg 119:340-346

33. Stout KK, Broberg CS, Book WM, Cecchin F, Chen JM, Dimopoulos K et al (2016) Chronic heart failure in congenital heart disease: a scientific statement from the American Heart Association. Circulation. 133:770-801

34. Engelfriet $P$, Boersma E, Oechslin E, Tijssen J, Gatzoulis MA, Thilén U et al (2005) The spectrum of adult congenital heart disease in Europe: morbidity and mortality in a 5 year follow-up period. Eur Heart J 26:2325-2333

35. Khairy P, Femandes SM, Mayer JE Jr, Triedman JK, Walsh EP, Lock JE, Landzberg MJ (2008) Long-term survival, modes of death, and predictors of mortality in patients with Fontan surgery. Circulation 117:85-92

36. Khambadkone S (2008) The Fontan pathway: what's down the road? Ann Pediatr Cardiol 1:83-92

37. Boucek MM, Edwards LB, Keck BM et al (2002) The Registry of the International Society for Heart and Lung Transplantation: Fifth Official Pediatric Report-2001 to 2002. J Heart Lung Transplant 21:827-840

38. Davies RR, Sorabella RA, Yang J et al (2012) Outcomes after transplantation for "failed" Fontan: a single-institution experience. J Thorac Cardiovasc Surg 143(1183-1192):e4 54

39. Karamlou T, Diggs BS, Welke K et al (2012) Impact of single-ventricle physiology on death after heart transplantation in adults with congenital heart disease. Ann Thorac Surg 94:1281-1287 discussion 1287- 1288

40. Mertens L, Hagler DJ, Sauer U et al (1998) Protein-losing enteropathy after the Fontan operation: an international multicenter study. PLE study group. $J$ Thorac Cardiovasc Surg 115:1063-1073

41. Malcic I, Sauer U, Stern H et al (1992) The influence of pulmonary artery banding on outcome after the Fontan operation. J Thorac Cardiovasc Surg 104:743-747

42. Nazlee Tabarsi MD, Meijiao Guan PD, Jacob Simmonds M et al (2017) Metaanalysis of the effectiveness of heart transplantation in patients with a failing Fontan. Am J Cardiol 119(8):1269-1274

43. Jokinen JJ et al (2010) Natural course and risk factors for impaired renal function during the first year after heart transplantation. J Heart Lung Transplant 29(6):633-640

44. Puttarajappa CM, Bernardo JF, Kellum JA (2019) Renal complications following lung transplantation and heart transplantation. Crit Care Clin 35(1):61-73

45. Lund LH, Edwards LB, Kucheryavaya AY et al (2013) The Registry of the International Society for Heart and Lung Transplantation: thirtieth officia adult heart transplant report-2013; focus theme: age. J Heart Lung Transplant 32(10):951-964

\section{Publisher's Note}

Springer Nature remains neutral with regard to jurisdictional claims in published maps and institutional affiliations.

\section{Submit your manuscript to a SpringerOpen ${ }^{\circ}$ journal and benefit from:}

- Convenient online submission

- Rigorous peer review

- Open access: articles freely available online

- High visibility within the field

- Retaining the copyright to your article

Submit your next manuscript at $\boldsymbol{\nabla}$ springeropen.com 